\title{
Modelagem do escoamento superficial a partir das características físicas de alguns solos do Uruguai
}

\author{
Runoff modeling from soil physical characteristics in different places in Uruguay
}

\author{
Renato Beppler SpohrI Reimar Carlesso"I Claudio García GallárretaII \\ Fernando García Préchac ${ }^{\mathrm{IV}}$ Mario García Petillo ${ }^{\mathrm{IV}}$
}

\section{RESUMO}

Os objetivos deste trabalho foram determinar $e$ modelar o escoamento superficial para solos com diferentes características físicas a partir de diferentes intensidades de chuva. Foram realizadas chuvas simuladas em diferentes solos, no Uruguai. Chuvas artificiais com intensidades de 30, 60 e $120 \mathrm{~mm} \mathrm{~h}^{-1}$ foram aplicadas utilizando-se um simulador estacionário de bicos múltiplos e oscilantes. Em cada solo foram determinados o tempo de início e a taxa de escoamento superficial, além da chuva (quantidade, duração e intensidade), declividade do terreno, matéria seca na superfície e cobertura do solo, densidade (do solo e de partícula), porosidade do solo (macro, micro e total), textura (argila, silte e areia), umidade inicial e saturação do solo. Foi utilizado o modelo modificado de Smith para estimativa do escoamento superficial. As perdas acumuladas por escoamento superficial foram de $64,32,30$ e $15 \%$ do total aplicado para Vertissolo 1, Chernossolo, Argissolo e Vertissolo 2, respectivamente. Há uma relação inversa entre o tempo de início do escoamento e a taxa constante de escoamento superficial, independentemente das condições da superfície do solo e da chuva. Isso está associado à intensidade da chuva, pois quanto mais esta aumentar, menor é o tempo de início do escoamento e maior é a taxa constante de escoamento superficial. O modelo modificado de Smith estima melhor o escoamento superficial sob condições de elevada umidade do solo.

Palavras-chave: escoamento superficial, física do solo, intensidade da chuva, simulador de chuva.

\section{ABSTRACT}

The objective of this research was to determinate and modeling the runoff for different soils classes based on different simulated rainfall intensities (30, 60 and 120 $\mathrm{mm} \mathrm{h}^{-1}$ ) in different soils in Uruguay. A portable rainfall simulator with multiple nozzles was used to simulate different rainfall intensities. On each soil was measured the initial time and rate of runoff, rainfall (total, duration and intensities), direction of slope, crop residue and cover percentage, soil densities (bulk and particle), soil porosity (bulk, macro and micro), textural fractions (clay, silt and sand), initial and saturated soil moisture. The runoff was estimated with Smith's modified model. The accumulate runoff losses were 64, 32, 30 e 15\% from the total rainfall, for Vertissolo 1, Chernossolo, Argissolo e Vertissolo 2, respectively. The relationship between initial runoff and the runoff rate was inversively, independently of the soil surface and rainfall conditions. Increasing rainfall intensity decreases the initial runoff time and increase runoff rate. Smith's modified model provides a better runoff estimated in soils with high soil moisture content.

Key words: runoff, soil physics, rainfall intensity, rainfall simulator

\section{INTRODUÇÃO}

Os fatores que influenciam a infiltração de água no solo interferem também no escoamento superficial resultante. De modo geral, sob uma intensidade constante de chuva, a infiltração e o escoamento superficial são processos antagônicos: à medida que um diminui (infiltração) o outro aumenta (escoamento), até atingirem certo equilíbrio dinâmico (estabilização). Segundo PRUSKI et al. (2003), a cobertura e os tipos de uso do solo, além de seus efeitos

ICentro de Ciências Agrária de Itaqui, Universidade Federal do Pampa (UNIPAMPA), Itaqui, RS, Brasil.

IIDepartamento de Engenharia Rural, Universidade Federal de Santa Maria (UFSM), 97105-900, Santa Maria, RS, Brasil. E-mail: carlesso@ccr.ufsm.br. Autor para correspondência.

IIIPesquisador do Instituto Nacional de Investigação Agropecuária do Uruguai (INIA), Montevidéu, Uruguai.

${ }^{\text {IV} F a c u l d a d e ~ d e ~ A g r o n o m i a ~ d a ~ U n i v e r s i d a d e ~ d a ~ R e p u ́ b l i c a, ~ M o n t e v i d e ́ u, ~ U r u g u a i . ~}$ 
sobre as condições de infiltração da água no solo, exercem importante influência na interceptação da água advinda da chuva. Quanto maior a porcentagem de cobertura vegetal, a rugosidade da superfície do solo e a evapotranspiração da cultura, maiores serão as taxas de infiltração de água no solo quando ocorrer uma chuva e, conseqüentemente, menores serão as perdas por escoamento superficial. A inclinação do declive do terreno é outro fator que influencia fortemente as perdas de solo e água por erosão hídrica, pois, à medida que ela aumenta, maiores serão o volume e a velocidade do escoamento superficial e menor será a infiltração de água no solo. Com isso, aumenta a capacidade de transporte das partículas de solo pela enxurrada, assim como a própria capacidade desta de desagregar solo por ação de cisalhamento, principalmente quando concentrada nos sulcos direcionados no sentido da pendente do terreno (COGO et al., 2003).

A chuva efetiva ou aproveitável é um dos elementos básicos a ser considerado na equação do balanço hídrico para determinar os requerimentos de irrigação das culturas, ocupando um papel fundamental no planejamento da irrigação, o uso eficiente dos recursos hídricos e o dimensionamento das obras e dos sistemas de irrigação (ROMERO \& GRANÃ, 1999). Segundo SILVA et al. (1994), em um manejo adequado da irrigação, a quantidade de água a ser aplicada à cultura é a diferença entre a demanda da evapotranspiração e a chuva efetiva. Vários fatores influem na porção efetiva da quantidade total de chuva, os quais podem atuar isoladamente ou interagindo com outros. Qualquer fator que afete a infiltração, o escoamento superficial ou a evapotranspiração, tem influência no valor da chuva efetiva. A determinação da chuva efetiva é de grande relevância para a agricultura, visto que essa parcela da chuva é realmente aquela que estará contribuindo com a água disponível do solo. Assim, a determinação das perdas de água por escoamento superficial pela chuva natural é essencial para o entendimento e a quantificação de processos hidrológicos. Estudos confiáveis com chuva natural requerem vários anos de medidas para obter uma amostragem representativa dos eventos de chuva. Além disso, a natureza irregular da chuva natural impede a intensiva coleta de dados durante a ocorrência do evento. Assim, para possibilitar estudo em períodos mais curtos e com maior controle das intensidades de chuva, tem-se utilizado chuvas artificiais produzidas por simuladores de chuva (SILVA et al., 2001).

Este trabalho teve como objetivos determinar e modelar as perdas de água por escoamento superficial em solos com diferentes características físicas, a partir de diferentes intensidades de chuvas simuladas em alguns solos do Uruguai.

\section{MATERIAL E MÉTODOS}

O trabalho foi conduzido no Uruguai, nas áreas experimentais do Instituto Nacional de Investigación Agropecuária - INIA. Os solos dos locais La Magnolia (latitude 3142'34" S e longitude 5549'26" W) e Palo a Pique (latitude $33^{\circ} 15^{\prime} 50^{\prime \prime}$ S e longitude $54^{\circ} 29^{\prime} 42^{\prime \prime}$ W) foram classificados como Argissolo Vermelho-Amarelo eutrófico abrúptico e Chernossolo Ebânico órtico típico, respectivamente. Os solos dos locais La Estanzuela (latitude $34^{\circ} 20^{\prime} 33^{\prime \prime}$ S e longitude $57^{\circ} 43^{\prime} 23^{\prime \prime}$ W) e El Junco (latitude $31^{\circ} 11^{\prime} 15^{\prime \prime}$ S e longitude $57^{\circ} 22^{\prime} 23^{\prime \prime} \mathrm{W}$ ), convencionados como Vertissolo 1 e Vertissolo 2, respectivamente, foram ambos classificados como Vertissolo Ebânico órtico típico (STRECK et al., 2002).

O delineamento experimental utilizado foi o inteiramente casualizado, bifatorial, com seis repetições, em que o fator $\mathrm{A}$ foi constituído de três intensidades de chuva simulada, 30, 60 e $120 \mathrm{~mm} \mathrm{~h}^{-1}$, e o fator B foi constituído de duas chuvas simuladas, chuva 1 e chuva 2 (a segunda chuva era realizada no mesmo local, 24 horas após a primeira).

As chuvas simuladas foram aplicadas utilizando-se um simulador estacionário de bicos múltiplos e oscilantes, instalado a 2,45 metros acima da superfície do solo. A pressão de saída da água dos bicos foi mantida em 41,4kPa. Para cada aplicação de chuva simulada, seis parcelas foram delimitadas por chapas metálicas cravadas no solo, contendo na parte inferior uma calha coletora, para coletar a água de escoamento superficial. As dimensões das parcelas foram de $1,0 \times 0,5 \mathrm{~m}\left(0,5 \mathrm{~m}^{2}\right)$. O tempo início de escoamento superficial foi determinado quando um filete contínuo de água começou a escoar na calha coletora, e a superfície apresentou encharcamento. Durante as avaliações, as coletas dos volumes de água escoados eram realizadas em intervalos de cinco minutos. $\mathrm{O}$ volume de escoamento superficial foi avaliado até tornar-se constante ou até o tempo máximo de 120 minutos, para cada chuva simulada.

A declividade dos locais foi determinada em cada ensaio, com a utilização de um nível de mangueira. A porcentagem de cobertura do solo com resíduo vegetal foi determinada pelo método da contagem de pontos quadrados, em uma malha de 72 quadriculas, a partir de fotografias digitais, contando-se o número de pontos com cobertura em relação aos pontos sem cobertura e, a partir disso, calculado-se a porcentagem de cobertura. A matéria seca de resíduo vegetal na superfície do solo foi determinada por meio da coleta (em três locais determinados aleatoriamente), secagem (em estufa a $65^{\circ} \mathrm{C}$ até obter-se matéria constante) e 
pesagem do resíduo vegetal contido em uma área de $0,25 m^{2}$.

A umidade inicial do solo, antes de cada chuva simulada, foi determinada a partir da coleta de amostras deformadas da camada superficial do solo (0 a $10 \mathrm{~cm})$. A determinação da umidade gravimétrica foi realizada utilizando-se metodologia descrita por BERNARDO (2002). Para classificar a umidade inicial do solo em alta, média ou baixa, utilizou-se o índice de precipitação pluvial antecedente (IPA) proposto por SHAW (1964):

$$
\mathrm{IPA}=\mathrm{P}_{-1}+\frac{\mathrm{P}_{-2}}{2}+\frac{\mathrm{P}_{-3}}{3}+\frac{\mathrm{P}_{-4}}{4}+\frac{\mathrm{P}_{-5}}{5}+\frac{\mathrm{P}_{-6}}{6}
$$

em que: IPA é o índice de precipitação pluvial antecedente; $\mathrm{P}_{-1}$ a $\mathrm{P}_{-6}$ refere-se às precipitações pluviais ou chuvas, em mm, ocorridas do dia -1 (ontem) ao dia 6 (seis dias anteriores ao dia de hoje).

Em uma área adjacente ao local onde o simulador foi instalado, foram coletadas amostras de solo, com estrutura indeformada na camada de 0 a 10 cm para determinações em laboratório da porosidade total, macroporosidade, microporosidade e densidade do solo. Para as análises de textura do solo e densidade de partículas, foram coletadas amostras com estrutura deformada na camada descrita acima. As determinações analíticas de textura, densidade de partículas, densidade e porosidade do solo foram realizadas conforme métodos descritos pela EMBRAPA (1979). As umidades correspondentes ao ponto de saturação e tensão de $-0,006 \mathrm{MPa}$ foram utilizadas como correspondentes à porosidade total e à microporosidade desse solo, respectivamente. A macroporosidade foi calculada pela diferença entre a porosidade total e a microporosidade.

O modelo matemático usado para descrever o escoamento superficial do solo deriva do modelo determinado por Smith (ALVES \& CABEDA, 1999), que descreve a infiltração de água no solo, com modificações apresentadas por Cabeda (ALVES \& CABEDA, 1999):

$\mathrm{i}=\left(\mathrm{R}-\mathrm{i}_{\mathrm{c}}\right) \times\left(\frac{\mathrm{t}_{\mathrm{e}}}{\mathrm{t}}\right)^{\mathrm{b}}+\mathrm{i}_{\mathrm{c}}$, para $\mathrm{t}>\mathrm{t}_{\mathrm{e}}$

em que, i é a taxa de infiltração em um tempo $\mathrm{t}\left(\mathrm{mm} \mathrm{h}^{-1}\right)$; $\mathrm{R}$ é a intensidade constante de chuva $\left(\mathrm{mm} \mathrm{h}^{-1}\right)$; i é a taxa constante de infiltração $\left(\mathrm{mm} \mathrm{h}^{-1}\right)$; $\mathrm{e}_{\mathrm{e}}$ é o tempo de início de escoamento da água sobre a superfície do solo (minutos); t é o tempo após o início do escoamento (minutos) e b é o parâmetro de ajuste do modelo.

Como a infiltração de água no solo e o escoamento superficial são processos antagônicos, ou seja, o aumento dos valores de um causa a redução dos valores do outro em igual magnitude (sob intensidade constante de chuva), foram realizadas as seguintes modificações no modelo: (i) substituindo-se o termo " $\mathrm{R}-\mathrm{i}$ " pela taxa constante de escoamento $\left(e_{c}\right)$ em $\mathrm{mm} \mathrm{h}^{-1}$; (ii) subtraindo-se 1 do resultado da ,

expressão “ $\left(\frac{t_{e}}{t}\right)^{b}$ ” e (iii) excluindo-se o termo “+ $i_{c}$ ” na equação 2, assim obteve-se:

$\mathrm{e}=\mathrm{e}_{\mathrm{c}} \times\left\{1-\left(\frac{\mathrm{t}_{\mathrm{e}}}{\mathrm{t}}\right)^{\mathrm{b}}\right\}$, para $\mathrm{t}>\mathrm{t}_{\mathrm{e}}$

em que $e$ é a taxa de escoamento superficial em um tempo $\mathrm{t}\left(\mathrm{mm} \mathrm{h}^{-1}\right)$. O escoamento superficial acumulado $\left(e_{a}\right)$ foi obtido por meio da integração da taxa de escoamento superficial em função do tempo.

Foram feitas análises de regressão linear múltiplas em que foram estimado os parâmetros da equação $3\left(e_{c}, t_{e}, b\right)$ para as variáveis independentes incluídas no modelo, usando a opção stepwise do SAS (Statistical Analysis System), em nível de 5\% de probabilidade de erro. As variáveis independentes utilizadas nessa opção foram: chuva (quantidade, duração e intensidade), declividade do terreno, matéria seca na superfície e cobertura do solo, densidade (do solo e de partícula), porosidade do solo (macro, micro e total), textura (argila, silte e areia), umidade inicial e de saturação do solo. Na definição das equações de regressão linear múltiplas para predizer os parâmetros do modelo, foi estabelecido que o comportamento de uma característica na equação deve afetar o parâmetro a ser predito (variável dependente) de forma consistente com os conhecimentos empírico e teórico do processo.

\section{RESULTADOS}

Os solos avaliados apresentaram uma reduzida macroporosidade (Tabela 1). Em parte, isso pode ser explicado pela presença de argilomineral (montmorilonita) com característica expansiva, presente no Vertissolo 2 e Vertissolo 1. Segundo Browning, citado por REICHERT et al. (1992), a expansão da argila reduz a porosidade total e o diâmetro médio de poros, de tal forma que os poros não-capilares se transformam em capilares e poros capilares podem ser completamente obstruídos.

Os menores valores de porcentagem de cobertura do solo foram observados no Vertissolo 2 e Argissolo (Tabela 1). Esse resultado está diretamente relacionado com a quantidade de matéria seca de resíduos vegetais na superfície do solo, que também foi menor nesses dois solos, em comparação com os 
Tabela 1 - Valores médios da densidade de partícula e do solo, porosidade (total, macro e micro), textura (argila, silte e areia), matéria de resíduos vegetais, cobertura do solo e declividade do terreno nos diferentes solos, no Uruguai.

\begin{tabular}{|c|c|c|c|c|}
\hline Variável & Argissolo & Chernossolo & Vertissolo 1 & Vertissolo 2 \\
\hline Densidade do solo $\left(\mathrm{Mg} \mathrm{m}^{-3}\right)$ & 1,51 & 1,35 & 1,29 & 1,21 \\
\hline Densidade de partícula $\left(\mathrm{g} \mathrm{cm}^{-3}\right)$ & 2,71 & 2,67 & 2,65 & 2,60 \\
\hline Porosidade total $\left(\mathrm{cm}^{3} \mathrm{~cm}^{-3}\right)$ & 0,462 & 0,536 & 0,578 & 0,380 \\
\hline Macroporosidade $\left(\mathrm{cm}^{3} \mathrm{~cm}^{-3}\right)$ & 0,016 & 0,020 & 0,036 & 0,031 \\
\hline Microporosidade $\left(\mathrm{cm}^{3} \mathrm{~cm}^{-3}\right)$ & 0,446 & 0,516 & 0,542 & 0,349 \\
\hline Argila $\left(\mathrm{g} \mathrm{kg}^{-1}\right)$ & 110 & 210 & 400 & 490 \\
\hline Silte $\left(\mathrm{g} \mathrm{kg}^{-1}\right)$ & 80 & 400 & 220 & 440 \\
\hline Areia $\left(\mathrm{g} \mathrm{kg}^{-1}\right)$ & 810 & 390 & 380 & 70 \\
\hline Matéria seca de resíduos vegetais $\left(\mathrm{Mg} \mathrm{ha}^{-1}\right)$ & 4,4 & 6,1 & 6,1 & 0,9 \\
\hline Cobertura do solo (\%) & 73 & 100 & 100 & 55 \\
\hline Declividade terreno (\%) & 13,8 & 4,9 & 2,9 & 3,1 \\
\hline
\end{tabular}

demais. A partir de 6,0 $\mathrm{Mg}$ ha $^{-1}$ de matéria seca de resíduo na superfície do solo, a cobertura do solo manteve-se em $100 \%$. No entanto, a quantidade de matéria seca de resíduos vegetais e a porcentagem de cobertura do solo não foram as características determinantes das perdas de água por escoamento superficial, uma vez que os solos com menor porcentagem de cobertura apresentaram os menores valores de escoamento superficial (Tabela 2), quando comparados aos solos com $100 \%$ de cobertura. Esses resultados estão relacionados às características físicas do Vertissolo 2, que possui altos teores de argila com característica expansiva (que no momento dos testes apresentava fissuras) e do Argissolo (com elevados teores de areia). Isso modificou as características da superfície do solo e favoreceu a infiltração de água. Segundo BRANDÃO et al. (2007), solos argilosos bem estruturados (estrutura estável) podem apresentar taxas de infiltração tão altas quanto às taxas dos solos arenosos e apresentam, seguramente, taxas de infiltração maiores do que os solos argilosos com estrutura instável. Nesse sentido, CASTRO et al. (2006) observaram que há um

Tabela 2 - Valores médios de chuva (intensidade, duração e quantidade), escoamento superficial, umidade do solo (inicial e de saturação), tempo de início e taxa constante de escoamento superficial observados nas avaliações realizadas com chuva simulada nos diferentes solos.

\begin{tabular}{|c|c|c|c|c|c|c|c|c|c|c|c|c|}
\hline \multirow{2}{*}{ Variável } & \multicolumn{12}{|c|}{ 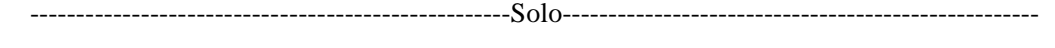 } \\
\hline & A & A & A & $\mathrm{C}$ & $\mathrm{C}$ & $\mathrm{C}$ & V1 & V1 & V1 & V2 & V2 & V2 \\
\hline \multicolumn{13}{|c|}{ 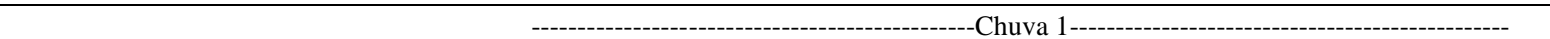 } \\
\hline Intensidade $\left(\mathrm{mm} \mathrm{h}^{-1}\right)$ & 102 & 42 & 20 & 82 & 52 & 51 & 116 & 65 & 35 & 116 & 60 & 32 \\
\hline Duração da chuva (min) & 60 & 60 & 120 & 120 & 120 & 60 & 60 & 60 & 90 & 120 & 120 & 120 \\
\hline Quantidade de chuva (mm) & 102 & 42 & 41 & 164 & 104 & 51 & 116 & 65 & 53 & 233 & 120 & 64 \\
\hline Escoamento superficial (mm) & 46,5 & 10,4 & 0 & 45,6 & 18,2 & 0 & 66,7 & 36,9 & 25,6 & 36,4 & 0 & 0 \\
\hline Umidade inicial $\left(\mathrm{cm}^{3} \mathrm{~cm}^{-3}\right)$ & 0,08 & 0,09 & 0,09 & 0,29 & 0,30 & 0,32 & 0,39 & 0,41 & 0,38 & 0,22 & 0,22 & 0,21 \\
\hline Umidade de saturação $\left(\mathrm{cm}^{3} \mathrm{~cm}^{-3}\right)$ & 0,47 & 0,47 & 0,45 & 0,58 & 0,52 & 0,51 & 0,57 & 0,58 & 0,59 & 0,37 & 0,40 & 0,38 \\
\hline Tempo de início do escoamento (min) & 5,3 & 15,0 & - & 41,8 & 70,0 & - & 9,1 & 20,3 & 30,0 & 62,0 & - & - \\
\hline Taxa constante de escoamento $\left(\mathrm{mm} \mathrm{h}^{-1}\right)$ & 49,8 & 11,9 & - & 45,9 & 23,4 & - & 87,4 & 63,3 & 31 & 32,1 & - & - \\
\hline Intensidade $\left(\mathrm{mm} \mathrm{h}^{-1}\right)$ & 99 & 52 & 29 & 103 & 59 & 32 & 112 & 61 & 32 & 119 & 62 & 34 \\
\hline Duração da chuva (min) & 60 & 60 & 120 & 60 & 60 & 90 & 60 & 60 & 90 & 60 & 90 & 120 \\
\hline Quantidade de chuva (mm) & 99 & 52 & 58 & 103 & 59 & 49 & 112 & 61 & 47 & 119 & 93 & 68 \\
\hline Escoamento superficial (mm) & 37,6 & 13,0 & 9,0 & 56,6 & 34,1 & 13,2 & 76,7 & 45,9 & 38,4 & 53,9 & 15,5 & 0 \\
\hline Umidade inicial $\left(\mathrm{cm}^{3} \mathrm{~cm}^{-3}\right)$ & 0,15 & 0,13 & 0,16 & 0,36 & 0,36 & 0,35 & 0,43 & 0,44 & 0,42 & 0,49 & 0,53 & 0,48 \\
\hline Umidade de saturação $\left(\mathrm{cm}^{3} \mathrm{~cm}^{-3}\right)$ & 0,47 & 0,47 & 0,45 & 0,58 & 0,52 & 0,51 & 0,57 & 0,58 & 0,59 & 0,37 & 0,40 & 0,38 \\
\hline Tempo de início do escoamento (min) & 6,3 & 17,1 & 50,0 & 9,1 & 13,5 & 40,7 & 5,8 & 11,3 & 18,2 & 3,4 & 18,6 & - \\
\hline Taxa constante de escoamento $\left(\mathrm{mm} \mathrm{h}^{-1}\right)$ & 42,1 & 17,9 & 7,4 & 72,3 & 48,6 & 19,1 & 91,4 & 59,2 & 30,8 & 62,8 & 13,3 & - \\
\hline
\end{tabular}

$\mathrm{A}=$ Argissolo, $\mathrm{C}=$ Chernossolo, $\mathrm{V} 1$ = Vertissolo 1, V2 = Vertissolo 2.

Ciência Rural, v.39, n.1, jan-fev, 2009. 
efeito significativo da rugosidade do terreno na redução das perdas por escoamento superficial sob reduzida quantidade de resíduos sobre o solo. No entanto, esse efeito é ocultado sob elevadas quantidades de resíduos. SILVEIRA \& SALVADOR (2000) testaram o efeito de quatro diferentes quantidades de massa seca de resíduos vegetais sobre as perdas de água por escoamento superficial. Os autores observaram que de 0 para $3 \mathrm{Mg} \mathrm{h}^{-1}$ de massa seca a redução nas perdas de água foi de aproximadamente $70 \%$. A partir dos $3 \mathrm{Mg}$ $\mathrm{h}^{-1}$, os efeitos da massa seca na redução das perdas de água foram bastante reduzidos. Dessa forma, o aumento da cobertura do solo reduziu as perdas, já que a água permanecia mais tempo retida na palha, retardando o escoamento superficial e facilitando a infiltração.

A intensidade final real de cada chuva aplicada não correspondeu à chuva programada devido à ocorrência de algumas rajadas de vento e de pequenas variações na pressão dos bicos do simulador durante a aplicação das mesmas. Nas avaliações com chuva simulada, as perdas acumuladas por escoamento superficial, em relação à quantidade total de chuva, foram de 64, 32, 30 e 15\%, para Vertissolo 1, Chernossolo, Argissolo e Vertissolo 2, respectivamente. O tempo de início do escoamento superficial, para a chuva 1 e 2, diminuiu com o aumento da intensidade da chuva e independentemente das condições da superfície do solo (Tabela 2). Segundo ALVES \& CABEDA (1999), isso ocorre porque, sob chuva de maior energia cinética, as alterações da superfície do solo ocorrem mais rapidamente, provocando o selamento superficial e diminuindo o tempo de início de escoamento superficial.

Ocorreu uma relação inversa entre o tempo de início do escoamento e a taxa constante de escoamento, independentemente do solo e da chuva, o que pode ser observado principalmente no Vertissolo 1. Isso está associado à intensidade da chuva, pois quanto mais esta aumentar, menor será o tempo de início do escoamento e maior será a taxa constante de escoamento superficial. Na maioria dos casos, houve uma redução no tempo de início de escoamento superficial, com o aumento da umidade inicial do solo e da intensidade da chuva, independentemente das condições da superfície do solo. SILVA et al. (2001), utilizando diferentes intensidades de chuvas simuladas em um Argissolo Vermelho-Amarelo, alcançaram resultados semelhantes.

Em todos os solos avaliados, as altas taxas constantes de escoamento superficial estão associadas com as maiores intensidades de chuvas simuladas, independentemente da condição de umidade inicial do solo (chuva 1 ou 2). Isso ocorre porque o solo possui uma determinada capacidade de infiltração, e o escoamento superficial tem início quando a chuva excede esse valor. A partir desse momento, a magnitude do escoamento superficial dependerá da intensidade da chuva. Quanto maior for a intensidade da chuva, maiores serão as perdas por escoamento superficial. REICHERT et al. (1992), utilizando sete diferentes solos, observaram um comportamento semelhante. VOLK et al. (2004), trabalhando em um solo com características semelhantes as do Vertissolo1 e com chuvas simuladas de $64 \mathrm{~mm} \mathrm{~h}^{-1}$, obtiveram resultados de tempo de início e da taxa constante escoamento superficial de 5 minutos e $51 \mathrm{~mm} \mathrm{~h}^{-1}$, respectivamente.

No Vertissolo 2, as perdas de água por escoamento superficial foram muito abaixo do esperado, uma vez que o solo encontrava-se seco e fissurado. Os resultados das avaliações com chuva simulada não expressaram uma situação esperada em condições mais elevadas de umidade do solo, assim, os dados obtidos dessas avaliações foram omitidos das análises realizadas a seguir.

A partir dos resultados da análise realizada por stepwise, a equação de regressão linear múltipla para estimativa da taxa constante de escoamento superficial $\left(e_{c}\right)$ pode ser expressada da seguinte forma: $e_{c}=-2,52+0,64 I C+0,074 A G-0,02 A R\left(r^{2}=0,82\right)$

em que, $e$ é a taxa constante de escoamento superficial em $\mathrm{mm} \mathrm{h}^{\mathrm{c}}$; ; $I C$ é a intensidade da chuva em $\mathrm{mm} \mathrm{h}^{-1}$; $A G$ é a fração de argila no solo em $\mathrm{g} \mathrm{kg}^{-1}$; e $A R$ é a fração de areia no solo em $\mathrm{g} \mathrm{kg}^{-1}$.

Variáveis importantes, tais como a duração da chuva, matéria seca na superfície, porcentagem de cobertura do solo, densidade do solo e macroporosidade, não foram significativas ( $\mathrm{P}>0,05)$. A partir dos resultados da análise realizada por stepwise, a equação de regressão linear múltipla para a estimativa do expoente " $b$ " do modelo modificado de Smith (equação 3) pode ser expressada da seguinte forma: $\mathrm{b}=14,01-0,03 \mathrm{IC}+0,37 \mathrm{DV}-10,78 \mathrm{DS}+51,0 \mathrm{PT}-45,0 \mathrm{MI}$ $\left(r^{2}=0,82\right)$

em que, $D V$ é a declividade do terreno em $\%$; DS é a densidade do solo em $\mathrm{Mg} \mathrm{m}^{-3}$; PT é a porosidade total do solo em $\mathrm{cm}^{3} \mathrm{~cm}^{-3}$ e $M I$ é a microporosidade do solo em $\mathrm{cm}^{3} \mathrm{~cm}^{-3}$.

Os resultados das equações de regressão linear múltipla para a estimativa do tempo de início do

Ciência Rural, v.39, n.1, jan-fev, 2009. 
escoamento superficial $\left(t_{e}\right)$ foram muito aquém do esperado. Entretanto, foi observado que havia uma alta de correlação do tempo de início do escoamento superficial com a taxa constante de escoamento superficial. Dessa forma, procurou-se determinar equações que relacionassem essas duas variáveis. Observou-se também que havia uma maior correlação entre as variáveis (tempo de início e taxa constante de escoamento superficial) quando maior fosse a umidade inicial do solo. A umidade inicial do solo é uma variável que tem grande influência no tempo de início do escoamento superficial e, para serem determinadas as equações para estimativa do tempo de início do escoamento superficial, foram utilizados os resultados obtidos sob elevada umidade inicial (Tabela 2). Para estimar o tempo de início do escoamento superficial sob diferentes umidades do solo, deve-se multiplicar os resultados das equações pelo fator de umidade inicial do solo (fu). Solo com umidade inicial alta, média ou baixa correspondem ao valor de fu de 1, 2 ou 4, respectivamente.

Os valores de fu foram determinados a partir da comparação do tempo de início do escoamento superficial entre a chuva 1 e a chuva 2 , em diversas simulações realizadas no Rio Grande do Sul e no Uruguai (SPOHR, 2007). Além disso, os valores de fu foram relacionados com diferentes índices de precipitação pluvial antecedente (IPA), para cada solo onde foram realizados os ensaios com chuvas simuladas. Os limites para o IPA foram determinados a partir do fracionamento em três partes iguais da lâmina de água contida entre os pontos correspondentes de 0 a -1,5 MPa da curva característica de água em cada solo (na camada de 0 a $20 \mathrm{~cm}$ ). Assim: IPA < 22 indica uma umidade do solo baixa, e fu será 4; IPA entre 23 e 44 indica uma umidade do solo média, e fu será 2 e IPA > 45 indica uma umidade do solo alta, e fu será 1 .

Assim, a equação logarítmica para determinação do tempo de início do escoamento superficial pode ser expressada da seguinte forma: $t_{e}=-12,58 \ln \left(e_{c}\right)+61,23 x$ fu $\left(r^{2}=0,61\right)$

em que, $t_{e}$ é o tempo de início do escoamento superficial em minutos; $e_{c}$ é a taxa constante de escoamento superficial em $\mathrm{mm} \mathrm{h}^{-1}$ e fu é o fator de umidade inicial do solo.

Na figura 1 são apresentados os valores de escoamento superficial acumulado observado nos ensaios realizados a campo, e os valores estimados para o Uruguai. Os valores de escoamento superficial acumulado $\left(e_{a}\right)$ foram obtidos a partir da integração da taxa constante de escoamento (e) no tempo. Os valores estimados, apresentados na figura 1, foram determinados utilizando-se no cálculo os parâmetros $e_{c}, t_{e}$ e $b$ obtidos a partir das equações de regressão multivariadas determinadas para o Uruguai (descritas anteriormente). Foi utilizado o valor de $f u=1$, ou seja, para solo com umidade inicial elevada.

No Argissolo o escoamento superficial acumulado (para as três intensidades de chuva) foi subestimado em 25\%. No Chernossolo e no Vertissolo 1 , os valores médios do escoamento superficial acumulado (para as três intensidades de chuva) foram superestimados em 7 e $3 \%$, respectivamente. Para as intensidades mais elevadas de chuva simulada (em torno dos $100 \mathrm{~mm} \mathrm{~h}^{-1}$ ), o desempenho do modelo de estimativa foi considerado satisfatório. Considerando a média das três chuvas com intensidades semelhantes, houve uma subestimativa de $4 \%$ nos valores do escoamento superficial acumulado. Nas intensidades intermediárias de chuva simulada (em torno dos $60 \mathrm{~mm}$ $\mathrm{h}^{-1}$ ), o desempenho do modelo de estimativa foi considerado satisfatório. Considerando a média das três chuvas com intensidades semelhantes, houve uma subestimativa de $15 \%$ nos valores do escoamento superficial acumulado. Nas baixas intensidades de chuva simulada (em torno dos $30 \mathrm{~mm} \mathrm{~h}^{-1}$ ), o desempenho do modelo de estimativa foi considerado ruim. Considerando a média das três chuvas com intensidades semelhantes, houve uma superestima de $38 \%$ no escoamento superficial acumulado.

\section{CONCLUSÕES}

O aumento da umidade inicial do solo e da intensidade da chuva reduzem o tempo de início do escoamento superficial, independentemente das condições da superfície do solo. Em um mesmo solo, o aumento da intensidade da chuva causa um aumento da taxa constante de escoamento superficial. A estimativa da taxa constante de escoamento superficial, realizada por meio de equações multivariadas contendo as variáveis intensidade da chuva e fração de argila e areia presente no solo, foi satisfatória para os solos avaliados. O modelo modificado de Smith estima satisfatoriamente as perdas de água por escoamento superficial para o Vertissolo 1. O modelo modificado de Smith estima melhor o escoamento superficial sob condições de elevada umidade do solo.

Ciência Rural, v.39, n.1, jan-fev, 2009. 


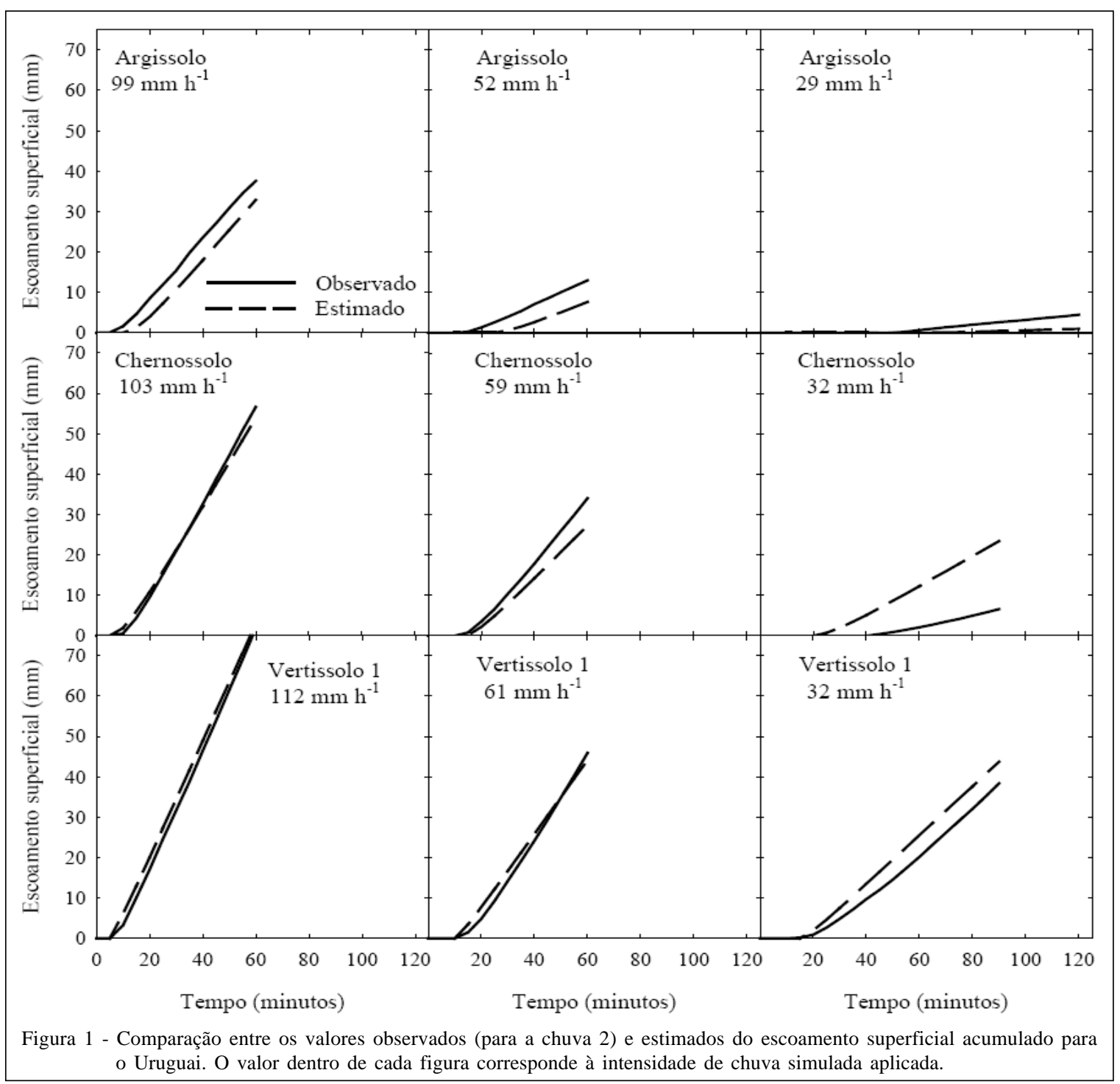

\section{REFERÊNCIAS}

ALVES, M.C.; CABEDA, M.S.V. Infiltração de água em um Podzólico Vermelho-escuro sob dois métodos de preparo, usando chuva simulada com duas intensidades. Revista Brasileira de Ciência do Solo, v.23, n.4, p.754-761, 1999.

BERNARDO, S. Manual de irrigação. 6.ed. Viçosa: UFV, 2002. 565p.

BRANDÃO, V.S. et al. Perdas de solo e caracterização física e micromorfológica de crostas formadas em solos sob chuva simulada. Engenharia Agrícola, v.27 n1, p.129-138, 2007.

CASTRO, L.G. et al. Interações na rugosidade superficial do solo pelo preparo e pela chuva e sua relação com a erosão hídrica. Revista Brasileira de Ciência do Solo, v.30, p.339352, 2006.

COGO, N.P. et al. Perdas de solo e água por erosão hídrica influenciadas por métodos de preparo, classes de declive e níveis de fertilidade do solo. Revista Brasileira de Ciência do Solo, v.27, p.743-753, 2003.

EMBRAPA. Serviço Nacional de Levantamento e Conservação do Solo. Rio de Janeiro: EMBRAPA, 1979. p.15-37.

PRUSKI, F.F. et al. Escoamento superficial. Viçosa: UFV, 2003. 88p.

REICHERT, J.M. et al. Selamento superficial e infiltração de água em solos do Rio Grande do Sul. Revista Brasileira de Ciência do Solo, v.16, p.289-298, 1992.

ROMERO, A.L.; GRAÑA, R.C. Modelos para el cálculo de la lluvia efectiva y su aplicación en caña de azúcar. Caña de Azúcar, v.17, p.3-20, 1999.

SHAW, R.H. Prediction of soil moisture under meadow. Agronomy Journal, v.56, p.320-324, 1964.

Ciência Rural, v.39, n.1, jan-fev, 2009. 
SILVA, C.L.A., et al. Modelagem da precipitação efetiva na cultura do milho. Pesquisa Agropecuária Brasileira, v.29, n.6, p.929-937, 1994.

SILVA, D.D. et al. Escoamento superficial para diferentes intensidades de chuva e porcentagens de cobertura num podzólico vermelho amarelo com preparo e cultivo em contornos. Engenharia Agrícola, v.21, n.1, p.1222-1230, 2001.

SILVEIRA, R.C.; SALVADOR, N. Uso de simulador de chuva no estudo de perdas de solo e água em parcelas com resíduos culturais de milho. Ciência Agrotécnica, v.24, n.3, p.718729, 2000.
SPOHR, R.B. Influência das características físicas do solo nas perdas de água por escoamento superficial no sul do Brasil e no Uruguai. 2007. 105f. Tese (Doutorado em Engenharia Agrícola) - Universidade Federal de Santa Maria.

STRECK, E.V. et al. Solos do Rio Grande do Sul. Porto Alegre: UFRGS, 2002. 107p.

VOLK, L.B.S. et al. Erosão hídrica influenciada por condições físicas de superfície e subsuperfície do solo resultantes do seu manejo, na ausência de cobertura vegetal. Revista Brasileira de Ciência do Solo, v.28, p.763-774, 2004. 